\title{
Does Normal Body Temperature Fluctuate when you are Watching Some Horror Scenes?
}

\author{
Muhammad Imran Qadir, Muhammad Asif* \\ Institute of Molecular Biology and Biotechnology, Baha Uddin Zakariya University, Multan, Pakistan. \\ *Corresponding Author: Muhammad Asif, Institute of Molecular Biology and Biotechnology, Baha \\ Uddin Zakariya University, Multan, Pakistan.
}

\begin{abstract}
The purpose of current task was to understand the relation between body temperature and watching horror movies. Total 125 subjects shared in this research work. Our body performances like a small furnace. It produces heat all the time. This heat accumulates from all day activities. When there is more or low heat out than usual, it clues to a problem. Everyone has dissimilar body temperature from normal range. The average body temperature is 98.6-degree Fahrenheit. But it can alter from the normal figure. It changes from $97\left(36.1^{\circ} \mathrm{C}\right)$ to $99^{\circ} \mathrm{F}\left(37.2^{\circ} \mathrm{C}\right)$ for adults and in case of babies and children, it persists higher between 97.9 and 100.4. It does not rest same all the day and throughout life. It is always fluctuating. It diverges due to your activities, age, gender, day time and food you eat. A body temperature higher from 100.4 is signified as fever. This condition is named as pyrexia. When temperature drops very low, it is hypothermia. Both states are fatal. The numbers of horror movies are accessible today. The science discovers that it activates body's fight or flight response when we follow some danger even it is not real at the moment. Our body's fight or flight machinery is regulated by hormones. The cortisol hormone is out when there is stress and it activates brain through adrenaline secretion. We realize some changes in our internal and external mechanism. The blood flow increases towards muscle and reduces towards chest and palm. So, we perceive cold around chest and palm because of sweating and dropping down of body's temperature. It was determined that here is non-significant linkage between normal body temperature and watching horror movies.
\end{abstract}

Keywords: Body Temperature, Horror Movies, Fahrenheit, Pyrexia, Hypothermia, Vomiting, Stiffed Neck.

\section{INTRODUCTION}

Our body acts like a small furnace. It emits heat all the time. This heat collects from all day activities. When there is more or low heat out than usual, it leads to a problem. Everyone has different body temperature from normal range. The standard body temperature is 98.6 -degree Fahrenheit. But it can fluctuate from the normal figure. It fluctuates from $97\left(36.1{ }^{\circ} \mathrm{C}\right)$ to $99{ }^{0} \mathrm{~F}\left(37.2{ }^{\circ} \mathrm{C}\right)$ for adults and in case of babies and children, it remains higher between 97.9 and 100.4. It does not stay same all the day and throughout life. It is always changing. It varies due to your activities, age, gender, day time and food you eat. A body temperature higher from 100.4 is considered as fever. This condition is called as pyrexia. When temperature falls very low, it is hypothermia. Both situations are fatal. No doubt, it feels uncomfortable in case of fever but it is not all bad for us. It is the indication that our body is resisting against germs invaded. A high temp. for constant three days, call for a physician immediately. You can have these symptoms like swelling throat, headache, chest pain, vomiting, stiffed neck and inflammation. These conditions are more severe to newborn babies especially.

Many of us watch scary movies on cinema and internet but they do not know about the facts of watching them. The numbers of horror movies are available today. The science explores that it activates body's fight or flight mechanism when we get some fear even it is not original at the moment. Our fight or flight system is regulated by hormones. The cortisol hormone is released when there is stress and it triggers brain through adrenaline secretion. We see some changes in our internal and external system. The blood flow rises towards muscle and lessens towards chest and palm. So, we observe cold around chest and palm because of sweating and dropping down of body's temperature. This condition is experienced while watching horror movies $(2,3)$. 
The intention of recent study was to comprehend relation of body temperature with watching horror movies (4-11).

\section{MATERIALS AND METHODS}

\subsection{Method to Record Body Temperature}

The body temperature was measured with digital mercury thermometer. There are different places that are used to record temperature of the body. We recorded the temperature in a lab. We kept thermometer in oral place under the tongue for accurate measurement. After 1 minute, we removed the thermometer and observed the reading. For next subject, we cleaned thermometer with cotton drenched in $70 \%$ ethanol. We asked question and got their answers. In this way, we calculated a valuable data for this research.

\subsection{Project Designing}

Total 125 subjects shared in this research work. These all were the biology undergraduates of BAHA UD DIN ZAKARIYA UNIVERSITY MULTAN, PAKISTAN. We computed the body temperature and wrote it on excel sheet for some computation. A survey page was provided to them. They replied the question. In this way, enough and good information were collected that helped in this research.

\subsection{Statistical Analysis}

The Microsoft Excel Application was used to evaluate the results. T- test was performed. $\mathrm{P}<0.1$ recommended as significant.

\section{RESULTS AND DISCUSSION}

Table1. Correlation of normal body temperature $(A v g \pm S D)$ and viewing scary movies.

\begin{tabular}{|c|c|c|c|}
\hline Sexual Characters & Loving Horror Movies & Hating Horror Movies & $p$-Value \\
\hline Male $\hat{} \propto$ & $\mathbf{9 7 . 4 1} \pm 2.02$ & $\mathbf{9 7 . 0 6} \pm \mathbf{3 . 0 9}$ & $\mathbf{0 . 7 8}$ \\
\hline Female $q$ & $\mathbf{9 6 . 8 8} \pm \mathbf{1 . 8 4}$ & $\mathbf{9 6 . 4 1} \pm \mathbf{1 . 8 5}$ & $\mathbf{0 . 2 1}$ \\
\hline Combined & $\mathbf{9 7 . 0 0} \pm 1.88$ & $\mathbf{9 6 . 5 1} \pm 2.07$ & $\mathbf{0 . 1 8}$ \\
\hline
\end{tabular}

$\mathbf{P}<\mathbf{0 . 1}$ considered as important.

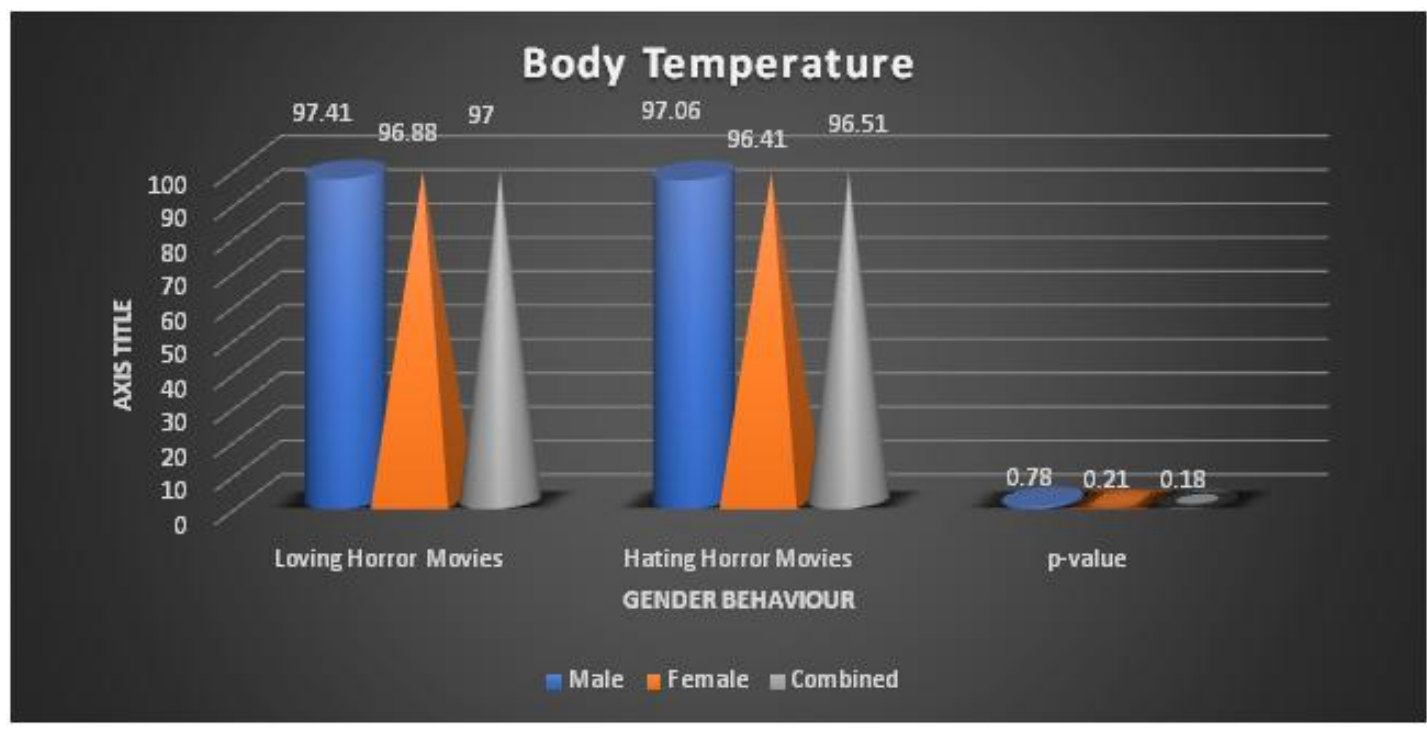

From the table (1) and graph, male and female had loved watching horror movies according to high average values $(97.41,96.88)$ respectively. While taking them together, it showed as usual result with larger mean value. In case of disliking scary movies, men and women had not disliked much viewing horror movies. They all liked watching such movies. But the $p$ values for them were disappointed as these values calculated are greater than original $p$ value. So, the results were non-significant for this study.

\section{DISCUSSION}

This study has given an important advancement in modern research. People have lower body temperature while watching horror movies. They were experimented and observed after seeing these events; the significant low temperature about $1^{\circ} \mathrm{C}$ was noted (1). 


\section{CONCLUSION}

It was decided that there is non-significant relation between normal body temperature and watching horror movies.

\section{REFERENCES}

[1] Tremblay,, Sylvie. "Your Body On: A Horror Movie." Sciencing, https://sciencing.com/your-body-on-ahorror-movie-13714006.html. 28 September 2018.

[2] Yoshihara K, Tanabe HC, Kawamichi H, Koike T, Yamazaki M, Sudo N, Sadato N. Neural correlates of fear-induced sympathetic response associated with the peripheral temperature change rate. NeuroImage. 2016 Jul 1; 134:522-31.

[3] Matsukawa K, Endo K, Ishii K, Ito M, Liang N. Facial skin blood flow responses during exposures to emotionally charged movies. The Journal of Physiological Sciences. 2018 Mar 1; 68(2):175-90.

[4] Qadir MI, Javid A (2018) Awareness about Crohn's Disease in biotechnology students. Glo Adv Res J Med Medical Sci, 7(3): 062-064.

[5] Qadir MI, Saleem A (2018) Awareness about ischemic heart disease in university biotechnology students. Glo Adv Res J Med Medical Sci, 7(3): 059-061.

[6] Qadir MI, Ishfaq S (2018) Awareness about hypertension in biology students. Int J Mod Pharma Res, 7(2): 08-10.

[7] Qadir MI, Mehwish (2018) Awareness about psoriasis disease. Int J Mod Pharma Res, 7(2): 17-18.

[8] Qadir MI, Shahzad R (2018) Awareness about obesity in postgraduate students of biotechnology. Int J Mod Pharma Res, 7(2): 14-16.

[9] Qadir MI, Rizvi M (2018) Awareness about thalassemia in post graduate students. MOJ Lymphology \& Phlebology, 2(1): 14-16.

[10] Qadir MI, Ghalia BA (2018) Awareness survey about colorectal cancer in students of M. Phil Biotechnology at Bahauddin Zakariya University, Multan, Pakistan. Nov Appro in Can Study, 1(3): NACS.000514.2018.

[11] Qadir MI, Saba G (2018) Awareness about intestinal cancer in university student. Nov Appro in Can Study, 1(3): NACS.000515.2018

Citation: Muhammad Imran Qadir, Muhammad Asif, "Does Normal Body Temperature Fluctuate when you are Watching Some Horror Scenes?" International Journal of Research Studies In Biosciences (Ijrsb), Vol. 7, no. 4, pp. 11-13, 2019. http://Dx.Doi.org/10.20431/2349-0365.0704003

Copyright: () 2019 Authors. This is an open-access article distributed under the terms of the Creative Commons Attribution License, which permits unrestricted use, distribution, and reproduction in any medium, provided the original author and source are credited. 